\section{A recepção da instrução programada como abordagem da análise do comportamento no Brasil nos anos 1960 e 1970}

\section{The reception of programmed instruction as an approach to behavioral analysis in Brazil in the 1960s and 1970s}

\section{Eustáquio José de Souza Jr.}

Professor; coordenador do curso de Psicologia/ Centro Universitário do Leste de Minas Gerais. Coronel Fabriciano - MG - Brasil eustaquiojunior@gmail.com

\section{Rodrigo Lopes Miranda}

Professor, Programa de Pós-graduação em Psicologia/ Universidade Católica Dom Bosco. Campo Grande - MS - Brasil dingoh@gmail.com

\section{Sérgio Dias Cirino}

Professor, Programa de Pós-graduação em Psicologia/ Universidade Federal de Minas Gerais. Belo Horizonte - MG - Brasil sergiocirino99@yahoo.com.br

Recebido em 13 out. 2015.

Aprovado em 11 ago. 2017.
SOUZA JR., Eustáquio José de;

MIRANDA, Rodrigo Lopes; CIRINO, Sérgio Dias. A recepção da instrução programada como abordagem da análise do comportamento no Brasil nos anos 1960 e 1970. História, Ciências, SaúdeManguinhos, Rio de Janeiro, v.25, n.2, abr.-jun. 2018, p.449-467.

Resumo

$\mathrm{O}$ artigo apresenta a recepção e circulação da instrução programada na Universidade Federal de Minas Gerais, como exemplo da apropriação da análise do comportamento no Brasil, e ilustra parte de tal apropriação nos anos 1960-1970, no contexto de reforma da educação superior e da influência sociointelectual estadunidense. Os resultados indicam que o recurso da instrução programada, para tornar-se autóctone, preconizou o protagonismo do aluno e sua autonomia do professor. As fontes indicam embates decorrentes de concepções preestabelecidas sobre o processo de ensino-aprendizagem e a influência estadunidense como elementos centrais para compreender a recepção e a circulação da instrução programada no Brasil.

Palavras-chave: história das tecnologias educacionais; história da psicologia no Brasil; história da análise do comportamento; circulação de conhecimentos.

Abstract

The article discusses the reception and circulation of programmed instruction at the Universidade Federal de Minas Gerais as an example of the appropriation of behavioral analysis in Brazil and sheds light on part of this appropriation in the 1960s and 1970s in the context of Brazil's higher education reform and of US social and intellectual influence. Results indicate that the indigenization of programmed instruction involved its circulation as an educational resource that emphasized the student's role and his autonomy from the teacher. Sources point to clashes that derived from preconceptions about both the teaching-learning process and US influence, key elements to understand the reception and circulation of programmed instruction in Brazil.

Keywords: history of educational technologies; history of psychology in Brazil; history of behavioral analysis; circulation of knowledge. 
$\mathrm{H}^{2}$ á alguns anos, diferentes campos da história têm refletido sobre os processos de circulação e apropriação de conhecimentos e práticas e sua relação com características locais (por exemplo, Ardigó, 2011; Gavroglu et al., 2008; Pratt, 1999; Raj, 2007, 2013). Um campo de destaque é o da história das ciências, em que diferentes conceitos têm sido delineados. Tem-se procurado explicitar as especificidades dos processos culturais locais e o papel ativo que as intervenções intelectuais, profissionais e políticas desempenham no processo de apropriação do conhecimento científico (Gavroglu et al., 2008). A problematização da fórmula "centro-periferia" critica opções historiográficas que pressupõem a possibilidade de "transmissão" unilateral do conhecimento de países do eixo Norte-Atlântico para outros contextos, supostamente carentes do conhecimento científico emanante de formações sociais consideradas centrais. Exemplo dessa crítica é o trabalho de Raj (2013), que se apropria da ideia de "zonas de contato", proposta por Mary Louise Pratt (1999), com a finalidade de compreender o funcionamento global da ciência a partir de um quadro referencial segundo o qual diferentes lugares fazem trocas e dialogam, modificando-se mutuamente. Assim, a pergunta "de onde vem a ciência?" modificar-se-ia para "quais as formas de circulação e hibridização dos conhecimentos científicos?". Essas perspectivas teórico-metodológicas nos ajudam a compreender que as práticas e os objetos científicos possuem não apenas temporalidades, mas, também, espacialidades. Além disso, elas permitem salientar características locais vinculadas aos processos de recepção e institucionalização das ciências.

Perspectivas similares às apresentadas anteriormente também se encontram presentes na história da psicologia. Nesse campo, elas procuram compreender a constituição dos conhecimentos psicológicos em face das características globais e locais em que emergem (Brock, 2006, 2014; Dagfal, 2004; Danziger, 2006; Pickren, 2009; Pickren, Rutherford, 2012; Castelo Branco et al., 2016). Entre os variados conceitos utilizados para fazer ver tal fenômeno da circulação e apropriação de saberes e práticas psicológicas, encontramos o de "indigenização", com o qual operamos neste artigo. A "indigenização" envolve a análise das formas de recepção e circulação dos conhecimentos psicológicos em relação às condições de cada localidade. Nessa perspectiva, objetiva-se compreender as formas pelas quais determinadas práticas e conhecimentos psicológicos circularam ao redor do mundo. Ademais, explora-se a conformação de objetos a partir de demandas locais, no momento em que foram apropriados, ativamente, por uma comunidade. Exemplificando, poder-seia questionar quais são as diferenças nos processos de apropriação de modelos teóricos da psicologia em diferentes países. Com quais condições socioculturais idiossincráticas tais modelos dialogaram durante o processo de apropriação?

Definindo "indigenização", Pickren (2009, p.87) afirma: "A indigenização assume muitas formas, como a incorporação de normas ocidentais que são reconfiguradas com conteúdos locais ou a rejeição de tais normas em favor de métodos e objetos que são nativos à cultura em questão". ${ }^{1}$ No caso deste texto, a "indigenização" nos ajuda a realçar mecanismos de apropriação de um arcabouço tecnológico, filosófico e científico estadunidense por uma comunidade brasileira. Uma comunidade interessada no incremento de recursos didáticos em um momento político marcado pelo desenvolvimentismo, presente nos períodos préinstauração de um governo ditatorial em 1964 e bastante incrementado por ele. O conceito 
nos permite, ainda, mapear, em escala regional, dinâmicas sociais, institucionais e científicas vinculadas à psicologia. Tal aspecto é potencialmente relevante se considerarmos as dimensões continentais do Brasil e, consequentemente, suas diferenças locais na apropriação e circulação de conhecimentos psicológicos.

Consideramos que o fenômeno eleito pode ser compreendido pelo prisma da “indigenização" por alguns motivos. À época, houve influência dos EUA no Brasil. Isso pode ser observado, por exemplo, pelos acordos do Ministério da Educação e Cultura (MEC) brasileiro com a Agência dos Estados Unidos para o Desenvolvimento Internacional (Usaid, na sigla em inglês). Tais acordos influenciavam a estrutura e o funcionamento educacional no país (Motta, 2014). Outro exemplo foi a crescente influência de teorias e conceitos estadunidenses na psicologia brasileira (Campos, Jacó-Vilela, Massimi, 2010). Conforme se verá, a instrução programada (IP) foi apropriada ativamente como tecnologia comportamental por professores interessados em práticas educativas e problemas educacionais daquele período, contando, aliás, com uma apropriação que implicou modificações claras das propostas estadunidenses em IP, no âmbito daquelas delineadas a partir da análise do comportamento. Cabe esclarecer que, por análise do comportamento, tomamos a posição teórico-metodológica dedicada à compreensão de fenômenos comportamentais alinhados à filosofia behaviorista radical de Burrhus Frederic Skinner (Matos, 1998; Todorov, Hanna, 2010).

Diante desse quadro, este artigo analisa formas de "indigenização" brasileira da IP, como tecnologia educacional estadunidense, a partir do caso da Universidade Federal de Minas Gerais (UFMG). Tal processo é analisado como um dos mecanismos de circulação da análise do comportamento no Brasil, nas décadas de 1960 e 1970. Para atingir tal objetivo, utilizamos fontes primárias textuais e orais. As primeiras foram compostas por artigos, livros e textos memorialísticos encerradas em diferentes arquivos e bibliotecas da UFMG e da Universidade de São Paulo (USP). As fontes orais foram produzidas por entrevistas com alunos e professores da UFMG que estiveram ligados à análise do comportamento em âmbito geral e à IP, em específico.

Visando ao objetivo proposto, o texto está dividido em três seções. Primeiramente, fazemos uma descrição da IP como tecnologia comportamental. Na sequência, abordamos circunstâncias socioculturais da recepção da IP no país. Por fim, introduzimos um estudo de caso da UFMG, que consistiu em lugar de recepção e circulação da IP, na linha de frente, com acadêmicos mantendo contato direto com a IP, e, paralelamente, na interação com atores brasileiros, familiarizados com a técnica e comprometidos com sua produção local. Logo, estimamos apresentar uma forma distinta de "indigenização" da análise do comportamento, a partir da apropriação da IP como tecnologia educacional no Brasil.

\section{Instrução programada, tecnologia comportamental e educação}

A IP pode ser tomada como um processo e um produto (Souza Jr., 2015). Como processo, ela consiste no ato da organização de conteúdos em unidades interligadas, que condicionam a progressão curricular ao desempenho apresentado pelo aprendiz em um programa de ensino. Como produto, a IP compreende o material didático autoinstrucional, 
promotor da progressão ou da retenção do aprendiz num dado programa, mediante a apresentação de respostas "corretas" ou "incorretas", emergentes do contato do estudante com o material programado. Logo, o cerne da IP é o processo de ensino/aprendizagem que se estabelece a partir do ritmo do aprendiz. A forma mais popular da IP, como produto, é o livro autoinstrucional, destinado à circulação de conteúdos escolares, científicos, técnicos e artísticos diversos. ${ }^{2}$

A IP mobilizou esforços políticos, econômicos e científicos de diferentes atores, especialmente nos EUA. Há propostas cujas características podem ser compreendidas como relacionadas à IP, especialmente as vinculadas às máquinas de ensinar, desde a transição do século XIX para o XX (Benjamin, 1988). Como exemplo, notam-se propostas de Sidney Leavitt Pressey (1888-1979) no início do século XX. Pressey propunha o uso de dispositivos de ensino no meio educacional, com o objetivo de economizar tempo e energia no desempenho de práticas docentes, tais como a correção de tarefas e a aplicação de testes acadêmicos. Uma análise de textos produzidos por Pressey (1960a, 1960b, 1960c) sugere influências do campo da psicologia comparada, particularmente das "leis da aprendizagem" de Edward Lee Thorndike (1874-1949) e seus colaboradores da Universidade de Columbia. Ademais, as considerações de Pressey no campo educacional já eram conhecidas no Brasil na década de 1930. Rota Jr. (2016) mostra como suas publicações circulavam junto a autores relacionados à psicologia, especialmente no que tange ao conceito de inteligência e de foco educativo centrado no aprendiz.

Entre as décadas de 1950 e 1970, nos EUA, fortaleceram-se discussões e propostas de IP e surgiram diversos atores associados à IP e ao desenvolvimento de máquinas de ensinar. Um dos principais proponentes da análise do comportamento foi Buhrrus Frederic Skinner (1904-1990), que contribuiu para o estabelecimento de uma tecnologia em IP a partir de esforços relacionados à construção de aparatos de ensino e com a publicação do livro programado The analysis of behaviour (A análise do comportamento) (Holland, Skinner, 1961). Na programação de ensino, Skinner defendeu um modelo linear de IP, exemplificado no livro mencionado. Esse tipo de programa apresentava questões que demandavam do aprendiz a complementação de frases lacunares, construídas para garantir (1) o acesso a conteúdo instrucional novo, disponibilizado pelo próprio programa, dispensando material didático adicional; (2) a promoção do processo descrito no item 1, por meio da realização de tarefas ou quadros sequenciais, organizados em etapas breves e com níveis de complexidade ascendentes; (3) que a resposta esperada quase sempre ocorresse mediante meticulosa elaboração das tarefas.

A apresentação do material programado em forma de livro impresso indica a opção pela divulgação da IP em mídia popular e de fácil acesso. O livro impresso contava com recursos já disponíveis para sua confecção, dispensando a construção de dispositivos mais custosos, tais como as "máquinas de ensinar".

O livro de Holland e Skinner obteve penetração no mercado editorial estadunidense e de outros países, com traduções realizadas para português, espanhol, alemão, francês e italiano, entre outras, além de ser referência para outras publicações sobre IP em diversos países (Callender, 1973; Muraro, 1973; Pereira, 1970; Witter, 1971). Em 1962, por exemplo, o periódico Science apontava a existência de vários cursos programados, como 250 em 
matemática nos níveis elementar, secundário e universitário nos EUA, sessenta em ciências e 120 destinados a estudos sociais (Skinner, 1983).

No Brasil, a IP circulou influenciando o processo de "indigenização" da análise do comportamento, nos campos editorial e educacional. Exemplos que sustentam esse apontamento são encontrados nas publicações da Cartilha da Amazônia (Witter, Kerr, Fonseca, 1977) e no projeto-piloto para o ensino de física (Bergvail, Joel, 1967). A primeira consistia em recurso didático dedicado à alfabetização e à familiarização com conceitos científicos para crianças com limitado acesso à educação formal no Norte brasileiro. O material foi elaborado segundo princípios da IP e conceitos relacionados à análise do comportamento (Witter, Kerr, Fonseca, 1977). O projeto-piloto da Organização das Nações Unidas para Educação, Ciência e Cultura (Unesco) para o ensino de física foi sediado na cidade de São Paulo e recorria à IP como estratégia de aprendizagem (Souza Jr.,

FACULDADE DE EDUCAÇÃO DA UFMG

DEpariamento de ciencias aplicadas a educacia

PSICOLOGIA DA APRENDIZAGEM

CONDICIONAMENTOS CLÁSSICO E OPERANTE

Programador: Helvécio Botelho Pereira Consulter: Ione Scarpelli Pereira

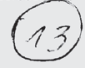

$\int$

N.Cham. 370.1523 P436p

Autor: Pereira, Helvécio Botelho.
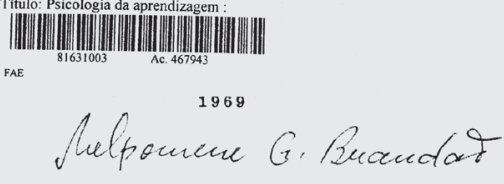

Figura 1: Capa do livro Psicologia da aprendizagem: condicionamentos clássico e operante (Pereira, Pereira, 1969)

2015). Sua elaboração contou com força-tarefa

que envolveu profissionais de países latino-americanos, bem como técnicos europeus da Unesco. O projeto se dedicava à reforma do ensino de ciências em países considerados carentes no campo educacional. A escolha do Brasil para acolher a sucursal do projeto para o ensino de física demonstra que o processo de circulação da IP no país baseava-se, consideravelmente, na utilização de conceitos relacionados à análise do comportamento, então em processo de apropriação local.

\section{Circunstâncias locais de recepção}

Desde as primeiras décadas do século XX, a educação nacional e sua renovação faziam parte dos debates de intelectuais, políticos e cientistas brasileiros. A renovação educacional esteve particularmente ligada à promoção da universidade e, consequentemente, ao investimento na constituição de um campo de produção científica no país. Na década de 1930, as discussões sobre investimentos materiais e simbólicos na universidade ganharam densidade (Cunha, 1988, 2007; Mendonça, 2000). Fomentando tais discussões, os cientistas construíram espaços a partir dos quais se colocavam como porta-vozes da modernização nacional. A ciência, assim, era apresentada como redentora dos atrasos sociais do Brasil, pois permitiria progressos industrial, urbano e econômico.

A partir da década de 1950, fortaleceram-se compreensões pragmáticas e desenvolvimentistas da educação brasileira, capitaneadas, especialmente, pelo MEC 
(Mendonça et al., 2006). Esse cenário sociopolítico no campo educacional acentuou o foco nos métodos de ensino e no desenvolvimento de pesquisas no meio universitário brasileiro. Isso implicava a promoção e o fortalecimento da comunidade científica nacional mediante intercâmbios com outros países e pelo investimento dos envolvidos com o empreendimento universitário. Por um lado, constatamos a criação de sociedades científicas no país: em 1948, foi criada a Sociedade Brasileira para o Progresso da Ciência (SBPC); em 1951, o Conselho Nacional de Desenvolvimento Científico e Tecnológico (CNPq) e, dois anos depois, a Coordenação de Aperfeiçoamento de Pessoal de Nível Superior (Capes). Por outro, observamos o investimento estrangeiro, especialmente estadunidense, no país, não só no campo econômico, como também cultural, educacional e científico. Encontramos com frequência fomento de pesquisas pela Fundação Rockefeller, Fundação Kellogg e Força Aérea Americana em projetos ligados, especialmente, ao campo educacional.

Em 1964 teve início no Brasil a ditadura civil-militar que perdurou até 1985. Um dos seus desdobramentos foi a organização de uma reforma universitária, instituída pela Lei n. 5.540/68 (Brasil, 28 nov. 1968). Ao lado dos debates sobre o fortalecimento da ciência e da formação de uma comunidade científica nacional, havia indicativos de que a universidade não atendia às demandas do mercado de trabalho, sendo necessários a expansão do ensino superior, o planejamento de ampliação de cursos de diferentes áreas, o desenvolvimento de tecnologias etc. A reforma universitária levada a cabo pelo regime civil-militar implicou mudanças, tais como a busca de eficiência na gestão da universidade, a expansão de vagas para estudantes, a organização da carreira docente, a criação de departamentos em substituição às cátedras, o fortalecimento da pesquisa e da pós-graduação (Motta, 2014).

Um exemplo da materialização de tais propostas reformistas da educação superior empreendidas no período foi a criação da Universidade de Brasília (UnB) (Cunha, 1988). Em suas palavras, Cunha (1988, p.18) afirmou que a reforma "consistia na radical mudança de organização dos recursos materiais e humanos da universidade". Como agentes da organização da UnB, nomes importantes da educação brasileira estiveram presentes, entre eles, Anísio Teixeira e Darcy Ribeiro. A criação da UnB guarda relação com a institucionalização da psicologia no país de modo amplo, bem como com a apropriação da análise do comportamento e da IP. Analistas do comportamento brasileiros como Carolina Martuscelli Bori (1924-2004) e Rodolpho Azzi (1927-1993) foram convidados a criar o Departamento de Psicologia da instituição. Em uma carta, Azzi afirmou: "Ele [o reitor] quer um departamento não apenas funcionando como deve funcionar, mas como um modelo de organização e ritmo de trabalho para os outros que virão ao Instituto de Ciências Humanas. Parece que apenas a psicologia (se formos) será capaz de satisfazer esses requisitos" (citado em Keller, 1983, p.59).

Esse cenário foi esteio para a promoção de um tipo de atuação em psicologia que fazia coro com os cientistas que se manifestavam em prol do desenvolvimento científico e renovação educacional como vetores de mudança social.

Todavia, a criação da UnB foi impactada pelo regime militar. A universidade foi palco de intensos conflitos políticos em decorrência dos quais grande parte dos professores abandonou-a logo no início de seu desenvolvimento (Salmeron, 2007). Entre esses professores estavam analistas do comportamento vinculados à IP (Todorov, Hanna, 2010). Esse tipo 
de ocorrência fez com que o projeto da "moderna" universidade brasileira acontecesse de maneira desarticulada. Seu modelo, entretanto, na época influenciou outras universidades no Brasil. A UFMG foi uma delas, tornando-se, aliás, lócus privilegiado para a alardeada "modernização" universitária (Cunha, 1988). Nas palavras de Cunha (1988, p.117-118), a UFMG tornou-se central nesse processo.

Primeiro, porque implantava a estrutura brasiliense, sem que os dirigentes das demais universidades tivessem de evocar a UnB, cercada de suspeitas desde sua fundação e desmoralizada pelas sucessivas crises de caráter mais policial do que acadêmico. Segundo, porque permitia às outras universidades, criadas a partir de unidades preexistentes e independentes, encontrar soluções para problemas similares, ao contrário da UnB, erigida a partir de um plano diretor sem antecedentes institucionais.

Um dos aspectos da "modernização" universitária carreada para a UFMG foi a própria análise do comportamento, bem como parte do processo de desenvolvimento da IP.

\section{Mecanismos de circulação da análise do comportamento na UFMG}

Na UFMG, a IP foi desenvolvida por atores interessados na promoção de novas condições de ensino em diferentes níveis educacionais (Cirino, Miranda, Souza Jr., 2012; Souza Jr., 2015). Por um lado, notamos agentes ocupados com o ensino superior, especialmente no ensino de psicologia. Por outro, encontramos professores dedicados ao ensino fundamental e alfabetização. No primeiro conjunto, salientamos a presença de Ione Scarpelli Pereira, que fez parte do grupo dos primeiros professores do curso de graduação em psicologia da UFMG. Ela introduziu em Belo Horizonte o livro de Holland e Skinner (1961), iniciando a sua adaptação. Sônia dos Santos Castanheira e Maria José Esteves de Vasconcellos foram suas alunas na primeira turma de graduação em psicologia da universidade, em 1963, e estudaram a aplicação de IP por meio da versão do livro de Skinner adaptada por Pereira. Posteriormente, Sônia e Maria José se tornariam professoras de psicologia experimental da mesma universidade, vinculando-se à análise do comportamento.

No segundo grupo, destacamos os professores Humberto Coelho de Carvalho e Helvécio Botelho Pereira. Ambos foram autores de livros em IP e atuaram na UFMG entre as décadas de 1960 e 1980 (Carvalho, 1970; Pereira, Pereira, 1969; Pereira, 1970). Além disso, relataram ter utilizado tal tecnologia comportamental em sala de aula. Magda Becker Soares foi orientadora da tese de doutorado de Humberto Coelho de Carvalho (1973), intitulada Elaboração e avaliação de um texto programado: estudo comparativo da aprendizagem genética de populações através do método de instrução programada aplicado a estudantes de nível médio e universitário. A tese foi defendida na Faculdade de Educação (FaE) e serviu de base para a publicação de livros em IP voltados para o ensino de genética, posteriormente escritos por Humberto Coelho de Carvalho (11 mar. 2014). Magda Becker Soares era professora da FaE da UFMG e dirigiu o Colégio Universitário (Coluni). Segundo lembranças de Humberto de Carvalho e Helvécio Pereira, ela convidou um grupo promotor de publicações e consultorias em IP do estado de São Paulo, composto pelos professores Samuel Pfromm Neto, Nelson Rosamilha, ambos do Instituto de Psicologia da USP (Ipusp), e Cláudio Zaki Dib, atuante no ensino do Instituto de 
Física, da mesma universidade. Os três estiveram em Belo Horizonte, em 1967, para ministrar um curso sobre IP, na Faculdade de Educação da UFMG (Pereira, 1970).

A propósito da menção à USP, ao observarmos o Ipusp na década de 1970, notamos impactos produzidos pela análise do comportamento nos anos de 1960 que contribuem para compreender sua recepção em Minas Gerais. Em 1961, chegou ao Brasil Fred Simmons Keller (1899-1996), amigo pessoal e colaborador de B.F. Skinner. Keller permaneceu um ano na USP como professor convidado, para ministrar aulas de psicologia comparada e psicologia experimental. Keller veio ao Brasil em uma licença sabática, com uma bolsa da Fundação Fulbright (Guedes et al., 2006, 2008; Todorov, 2006; Todorov, Hanna, 2010). Ele se definia como professor, mais do que como pesquisador (Keller, 1977; Kerbauy, 1996). Um elemento destacado da sua passagem pela USP, em 1961 e 1962, foi a instalação de laboratórios didáticos para o ensino de análise do comportamento e seu principal objeto, a caixa de Skinner (Cirino, Miranda, Cruz, 2012).

A importância do laboratório como dispositivo didático pode ser compreendida à luz do quadro da educação brasileira no período. No Brasil da década de 1960, surgiram diversas solicitações para o aumento de vagas nas universidades. A estruturação de um laboratório de análise do comportamento, como um laboratório de psicologia experimental, asseguraria a cientificidade da nova profissão de psicólogo e atenderia a um número maior de estudantes que ingressavam na universidade. Além disso, no ensino superior brasileiro da década de 1960, discutia-se a necessidade da formação de pesquisadores. O laboratório poderia contribuir para esse processo, conforme defendido pelos analistas do comportamento. O laboratório poderia atuar, também, como um vetor de disciplinarização dessa teoria, pois estabeleceu condições materiais para a criação de instrumentos brasileiros de análise do comportamento, especialmente a caixa de Skinner, pela Fundação Brasileira para o Desenvolvimento do Ensino de Ciências (Funbec). Em acréscimo, o laboratório influenciou o desenvolvimento de um modelo de ensino de psicologia experimental a ser aplicado nos cursos de psicologia em criação no país quando da regulamentação da formação (Brasil, 27 ago. 1962). O espaço do laboratório foi prolífico para a formação de um grupo inicial de brasileiros entusiastas da teoria. Nesse contexto, destacamos Carolina Bori, Maria Amélia Matos (1939-2005) e Rodolpho Azzi (1927-1993), que se comprometeram com o desenvolvimento da ciência no país e se opuseram ao regime militar na universidade. ${ }^{3}$

Registramos, assim, que a vinda de Keller pode ser compreendida como um exemplo dos investimentos estadunidenses nas Américas. No documento da Fundação Fulbright que divulgou os bolsistas contemplados naquele ano (Miranda, 2010) há referência a Fred Keller, em meio a outros seis professores vindos dos EUA para universidades brasileiras. Um dos investimentos de Keller no ensino de análise do comportamento foi a criação de um laboratório didático, promulgado como um "moderno curso de psicologia" (Keller, Bori, Azzi, 1964). Seu interesse pela educação encontrou pessoas também investidas nesse campo, especificamente Carolina Bori e Rodolpho Azzi. Juntos, eles produziram o Sistema Personalizado de Ensino ${ }^{4}$ (PSI, na sigla em inglês), tributário da experiência brasileira para implementação do curso de psicologia da UnB (Keller, Sherman, 1974). Portanto, o trio contribuiu para criar condições para a disseminação da análise do comportamento no Brasil. 
Sobre a UFMG e sua relação com a análise do comportamento, Soares (23 jan. 2014) afirmou: "nos anos 1960 a educação esteve muito ligada aos EUA. Então, o que ocorria lá, repercutia aqui. Eu acho que foi o caso da influência de Skinner aqui. Nesse período havia aquela mentalidade que o Brasil tinha de progredir, ser produtivo".

A influência estadunidense, nas lembranças de Soares, impactava as questões educacionais brasileiras, contando, aliás, com a participação de membros da comunidade científica do país. Acordos do MEC-Usaid (Kraftzik, 2006) e o Programa de Assistência Brasileiroamericana ao Ensino Elementar (Pabaee) (Paiva, Paixão, 2002) são exemplos de programas de cooperação firmados com finalidades relacionadas à ampliação da área de influência dos EUA nas Américas. Os EUA se colocavam como modelo de desenvolvimento científico, econômico e social para os países latino-americanos, para parte da intelectualidade brasileira incluída (Souza Jr., 2015). Percebemos, então, uma relação com a ideia de "progresso" do país, por meio do desenvolvimento científico e educacional, vinculada à adoção de práticas e modelos estadunidenses e europeus. Na análise de Soares (23 jan. 2014), esse cenário ajuda a compreender o porquê da circulação das propostas skinnerianas no país. De acordo com ela, o interesse estava na promoção de melhores práticas educativas, dados os variados problemas educacionais brasileiros na época. Na década de 1970, por exemplo, havia uma retenção de aproximadamente 15\% de estudantes do ensino fundamental (Souza, 2011). Assim, Soares (23 jan. 2014) faz coro à demanda de soluções para problemas educacionais e, na mesma direção, situa a IP na UFMG, na interseção entre a influência estadunidense e o interesse em mudanças na educação:

Havia um fracasso escolar muito grande, não é? Índices de reprovação em todas as séries, e tinha evasão escolar. Enfim, um fracasso da educação. A instrução programada apresentava uma proposta que parecia ajudar nesse problema. Algo que fascinou muito na época; mais do que os procedimentos como a instrução programada, foi a proposta de objetivos comportamentais.

Em sua análise, a proposta de programar o ensino por meio de objetivos comportamentais foi um fator que se difundiu fortemente, em especial nos cursos de pedagogia. Neles, ensinavam-se aos estudantes maneiras de construir objetivos comportamentais adequados a diferentes conteúdos. Nesse contexto, havia o enfoque na operacionalização dos objetivos comportamentais, que deveriam ser expressos como ações publicamente observáveis do alunado. Assim, o apelo da IP parecia residir na funcionalidade propiciada pelos "objetivos comportamentais", os quais consistiam na especificação das metas do processo de ensino/ aprendizagem, em termos operacionais ou, ainda, em comportamentos observáveis/ mensuráveis. A IP e os objetivos comportamentais surgiam como instrumentos interventivos sobre problemas educacionais brasileiros, cumprindo o papel de auxiliares para a aprendizagem dos estudantes, e não como métodos per se.

Ivone Pereira relembra aspectos da apropriação da IP na UFMG, mormente, a partir de sua adaptação informal do livro de Holland e Skinner (1961). No início da década de 1960, ela visitou a Universidade de Houston, como parte de um programa de cooperação Brasil-EUA para a formação de professores. Sobre essa viagem, relatou: 
Eu fiz uma visita aos EUA, e a análise do comportamento estava realmente no auge. A técnica da instrução programada tinha surgido e despertado bastante entusiasmo. Nós pegamos apenas esse material [O livro The analysis of behaviour] e trouxemos para a UFMG. O pessoal aqui [da UFMG] achou que a gente poderia utilizar e que seria uma coisa bem interessante. Então, eu comecei a traduzir esse livro (Pereira, 21 jan. 2014).

O interesse de Ivone Pereira devia-se ao otimismo que a IP promovia, dada a possibilidade de aplicação em diferentes níveis de ensino. Tal sentimento alinhava-se ao de seus colegas e se relacionava com a possibilidade de planejar o processo de ensino/aprendizagem de maneira mais clara (Pereira, 13 jan. 2014).

Na mesma direção, Soares (23 jan. 2014) manifestou sua visão acerca das possibilidades apresentadas aos profissionais da educação, por meio dos métodos de programação do ensino. Ela indicou que a proposta da IP skinneriana proporcionava grande clareza ao processo de ensino, em decorrência da decomposição do objetivo final em comportamentos observáveis. Em suas palavras:

Você definia onde você queria chegar. Com os objetivos comportamentais, você decompunha o caminho em passos e você ia levando o aprendiz a dar cada passo e imediatamente saber se deu um passo certo ou um passo errado e corrigir o passo errado. Isso dava uma tranquilidade, uma segurança, de que você estava orientando a pessoa estreitamente no caminho que ela tinha que seguir para que ela chegasse àquele comportamento que era importante que ela alcançasse (Soares, 23 jan. 2014).

Dessa forma, a IP permitiria ao professor criar condições mais claras de ensino/ aprendizagem. Ele poderia "se tranquilizar", uma vez que havia os objetivos comportamentais que indicariam onde a tarefa deveria chegar e como fomentar o acerto, em caso de erro. Além disso, fica em evidência a valorização da decomposição do objetivo comportamental em pequenas unidades de respostas que, organizadas em uma trajetória, levam à instalação do desempenho final esperado. Isso parece ter relação com o processo de modelagem estabelecido pela análise do comportamento.

Nesse cenário geral, Ione Pereira e Helvécio Pereira (professor de matemática na Faculdade de Filosofia, Ciências e Letras da UFMG) adaptaram o livro de Holland e Skinner (1961), intitulando-o Psicologia da aprendizagem: condicionamentos clássico e operante (Pereira, Pereira, 1969). Estudantes da primeira turma de graduação em psicologia da UFMG recordam-se de utilizar o livro na disciplina de psicologia da aprendizagem:

Ione foi minha professora de psicologia no terceiro ano e foi ela quem me mostrou o Holland-Skinner. Foi ela quem traduziu aquela instrução programada. Foi com ela que eu aprendi os conceitos iniciais de reforçamento, condicionamento. Foi Ione quem introduziu e publicou, em apostila, o livro do Holland-Skinner de instrução programada (Castanheira, 5 fev. 2009).

A psicologia da aprendizagem foi ministrada pela professora Ione, logo que ela voltou dos EUA e chegou de lá trazendo o Holland-Skinner. Nós tivemos a instrução programada do Holland e Skinner nas aulas da professora Ione em 1965; era uma tradução mimeografada. E aí foi a primeira notícia que eu tive de Skinner, não é?! (Vasconcellos, 5 mar. 2009). 
O livro era apresentado em partes, durante as aulas. A tradução "oficial" que Ione Pereira iniciou foi interrompida quando, em contato com pesquisadores de São Paulo, descobriu-se que o texto já estava traduzido e era utilizado em cursos paulistas. Essa aparente controvérsia sugere estudos adicionais sobre a relação entre o grupo paulista e os demais grupos de analistas do comportamento no Brasil. Entretanto, ela continuou utilizando sua adaptação nas aulas e, em 1969, publicou-a pela FaE-UFMG (ver Figura 1).

O material foi publicado pelo Departamento de Ciências Aplicadas à Educação (Decae), o que chama atenção, já que, na FaE-UFMG, havia um Departamento de Métodos e Técnicas de Ensino (DMTE). Isso pode sugerir que, para membros da UFMG, a IP e um livro de tal natureza consistiam em recursos para o ensino, e não em metódos e técnicas em si mesmos. Nos dois departamentos eram encontrados professores com diferentes formações, tais como ciências sociais, história, geografia. No Decae, seu interesse principal era a articulação de sua disciplina de origem com a educação. Assim, encontrávamos disciplinas de psicologia da educação, história da educação e filosofia da educação. O DMTE, por sua vez, congregava aqueles professores interessados no desenvolvimento de instrumentos e métodos didáticos para a promoção da educação. Seu foco estava na formação de professores para disciplinas específicas como, por exemplo, a formação do professor de matemática ou de química.

Essas características se entrelaçam com outras propostas de IP produzidas no Brasil por pessoas vinculadas à análise do comportamento. Azzi (1962) nos fornece um exemplo nessa direção. Ele apresentou diversas concordâncias e discordâncias no processo de "indigenização" da IP no Brasil. Embora tenha mantido seu referencial teórico alinhado à análise do comportamento, discutiu a utilização do termo "máquinas de ensinar", propondo o uso de "máquinas de aprender". Em sua análise, as máquinas, no processo educacional, são um recurso destinado à aprendizagem, e não uma nova metodologia. Ele evidenciava que o foco não deveria se manter no ensino, mas na aprendizagem.

Outro aspecto de destaque é que Psicologia da aprendizagem: condicionamentos clássico e operante não foi publicado no curso de psicologia da FFCL-UFMG, onde era utilizado, mas na FaE-UFMG. É fato que, desde a década de 1940, havia o ensino de psicologia para outros cursos da UFMG, antes da constituição do curso de graduação em psicologia, implementado em 1963 (Miranda, 2010). Cite-se, como exemplo, a presença de Pedro Parafita de Bessa (1923-2002) como docente de psicologia para o curso de pedagogia, nesse período. Posteriormente, em 1960, ele foi um dos fundadores do curso de graduação em psicologia da UFMG e seu primeiro diretor.

O manuscrito tinha encadernação bastante simples, composta pela junção dos cadernos individuais, presos por grampos centrais, possivelmente porque o material foi produzido para ser utilizado como um dos textos de apoio para aulas do curso de psicologia da UFMG. Não havia pretensões de circulação nacional. O exemplar consultado foi datilografado e fotocopiado. Nele, podemos ler o nome da antiga proprietária. Essas características sugerem que o texto poderia ser facilmente impresso e distribuído, com baixo custo de produção, o que é condizente com um material experimental e que seria utilizado num contexto restrito. A utilização de recursos de ensino com baixo custo foi, aliás, uma marca inicial dos envolvidos com a análise do comportamento na UFMG. A título de exemplo, foi instalado, em 1971, um laboratório, em um banheiro, com caixas 
de Skinner, de papelão, para experimentos com pombos. Essa prática era sustentada por um manual estadunidense, adaptado no Brasil. A versão estadunidense era Experiments in operant behavior (Experimentos em comportamento operante) (Reese, 1964), e a nacional, Análise experimental do comportamento: exercícios de laboratório com pombos (Kerbauy, 1970).

A adaptação brasileira de Holland e Skinner (1961) não apresenta sumário, prólogos ou agradecimentos, enquanto a produção estadunidense contém todos esses itens, com introduções específicas para o "instrutor" e para o "estudante". A seção de agradecimentos do livro estadunidense reporta colaborações, no sentido de aplicações prévias do programa a ser apresentado, sugerindo um esforço interinstitucional para a consolidação do projeto. A apresentação geral do texto brasileiro indica que ele foi produzido para atender a finalidades pedagógicas localizadas: disciplinas, na UFMG, para cursos de graduação em psicologia. Assim, não há indícios de aplicação de estudo-piloto, aspecto considerado crucial para a redação de textos programados. Essas diferenças reforçam as destinações contrastantes dos textos. No caso de Holland e Skinner (1961), o texto fora concebido para dar visibilidade a uma proposta de ensino, no formato de um manual geral de princípios de análise do comportamento, condizendo com o modelo linear desenvolvido pelos autores. Já o texto de Pereira e Pereira (1969) foi criado para ensinar princípios de aprendizagem, em disciplinas do curso de psicologia da UFMG. Portanto, sua finalidade era mais prática do que teórica.

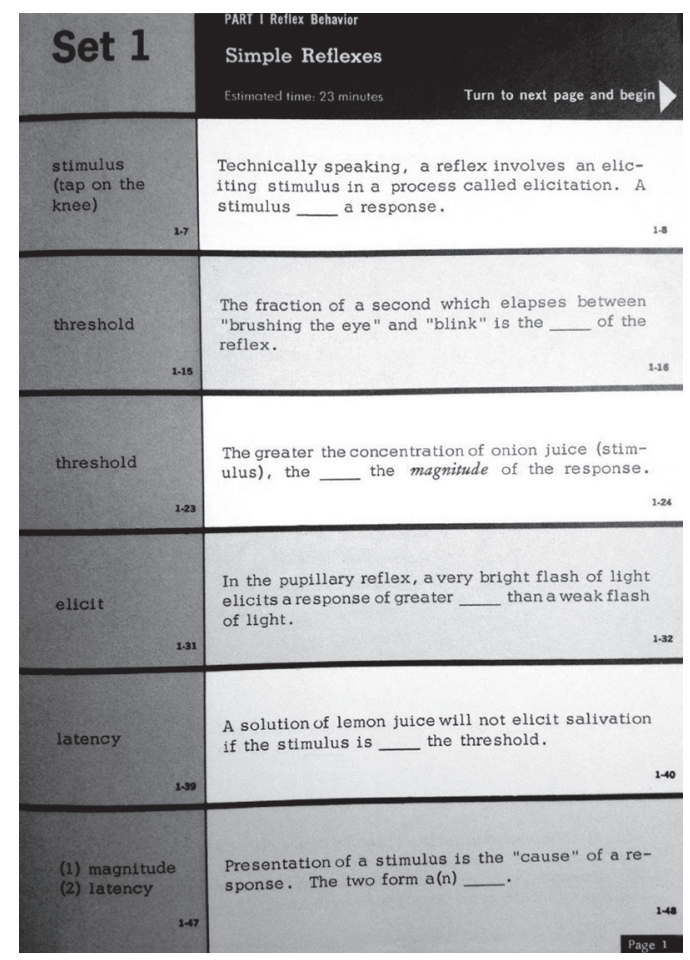

Figura 2: Excerto do texto programado The analysis of behavior (Holland, Skinner, 1961, p.1) 
A organização do texto de Holland e Skinner, contando com um quadro respondido por página, bem como com a apresentação da resposta correta apenas na página subsequente àquela onde figura a tarefa, é substancialmente diferente da configuração adotada em Pereira e Pereira (1969). O número de páginas e a quantidade de conteúdos abordados também são contrastantes. O conteúdo do texto estadunidense oferecia visão panorâmica de parte do que havia sido produzido e estava consolidado no campo da análise do comportamento (ver Quadro 1).

Quadro 1: Conteúdo programático de Holland e Skinner (1961)

\begin{tabular}{|l|}
\hline Comportamento reflexo \\
\hline Condicionamento operante: conceitos elementares \\
\hline Condicionamento operante: contingências exatas \\
\hline Modelagem \\
\hline Reforçamento intermitente \\
\hline Controle de estímulos \\
\hline Privação \\
\hline Emoção I \\
\hline Comportamentos de fuga e esquiva \\
\hline Emoção II \\
\hline Punição \\
\hline Análises científicas e interpretação de casos complexos \\
\hline Autocontrole \\
\hline Interpretação da personalidade \\
\hline
\end{tabular}

Fonte: Elaborado pelos autores com base em Holland, Skinner (1961).

O texto traz desde questões elementares do campo, até quadros que abordam análise de comportamentos complexos, como temas clássicos em psicologia, uso de drogas, transtornos de ansiedade, conceitualização de personalidade. O texto brasileiro serviria ao propósito de compreender apenas aspectos relacionados à aprendizagem (ver Quadro 2).

Quadro 2: Conteúdo programático de Pereira e Pereira (1969)

\begin{tabular}{|l|}
\hline Reflexo condicionado \\
\hline Generalização \\
\hline Discriminação \\
\hline Outros tipos de condicionamento de ordem superior \\
\hline Condicionamento operante \\
\hline
\end{tabular}

Fonte: Elaborado pelos autores com base em Pereira e Pereira (1969).

O manuseio do livro brasileiro nos fornece alguns indícios de dificuldades inerentes ao uso da IP. Primeiramente, chama a atenção o fato de o texto apresentar as respostas na mesma página do item a ser respondido, enquanto, no original estadunidense, a resposta está na folha que sucede a questão. Essa característica do texto brasileiro também estava 
presente em outras publicações nacionais, tais como Carvalho (1970). Em Pereira e Pereira (1969), cada item de um quadro deve ser respondido e, imediatamente, ter sua resposta conferida na mesma página. O sentido da leitura é da esquerda para a direita e de cima para baixo, assemelhando-se ao de um texto comum. As respostas ficam à esquerda das questões e devem ser cobertas pelo leitor, antes de escrevê-las no próprio livro ou em uma folha à parte. Há textos explicativos, que devem ser lidos antes de dar início aos itens de alguns quadros. Os itens podem conter de uma até três lacunas para preenchimento e há alternativas de múltipla escolha, que não requerem a escrita da resposta eleita, apenas a sua seleção. Há itens com orientações para ampliar a probabilidade de acerto, fornecendo as primeiras letras das respostas nas lacunas. Em segundo lugar, não há instruções sobre o manuseio do livro no texto brasileiro, o que pode reforçar a impressão de que o texto seria apresentado aos alunos pelo professor, a quem caberia indicar a forma correta do seu manejo. Sob outra perspectiva, esse aspecto contrasta com a proposta estadunidense de IP, que reserva ao professor a função de programar e esclarecer eventuais dúvidas, após a submissão ao programa.

O fato de Pereira e Pereira (1969) conter questões de múltipla escolha sugere mais um aspecto claro do processo de "indigenização". Por exemplo, observemos a página 2 (ver Quadro 3).

\section{Quadro 3: Exemplo de questão objetiva em Pereira e Pereira (1969)

\begin{tabular}{|c|c|}
\hline "Espirrar" é um(a) & (estímulo/resposta) \\
\hline
\end{tabular} \\ Fonte: Pereira e Pereira (1969).}

No item, são notáveis dois aspectos: (1) não há lacuna ou outro recurso que demande do aluno a redação de resposta escrita, e (2) o sujeito submetido ao programa é induzido a fazer uma opção entre duas alternativas. Skinner (1954) prescrevia a necessidade de haver atividade do sujeito sobre o conteúdo de um programa, devendo o aluno escrever sua resposta a partir da interação com os quadros do programa. Ele contraindicava a apresentação de itens de múltipla escolha que preconizassem o reconhecimento, em detrimento da rememoração e da produção escrita. Um aspecto que nos auxilia a compreender a possível presença de questões objetivas no texto brasileiro é a atuação de Helvécio Pereira na UFMG. Ele, junto à equipe fundadora do Coluni, ${ }^{5}$ atuou na implementação das questões de múltipla escolha naquele colégio (Soares, 23 jan. 2014). Tal fato parece explicar, pelo menos parcialmente, a presença dessa característica no texto de Pereira e Pereira (1969).

No contexto da UFMG, notamos que o processo de "indigenização" da IP, como tecnologia comportamental, relaciona-se à associação com a análise do comportamento. Exemplificando, Soares (23 jan. 2014) afirma: "Acredito que houve uma generalização muito grande. Que a instrução programada resolveria tudo: todos os problemas, todas as disciplinas, todos os conteúdos. Não é verdade! Ela servia pra determinados comportamentos objetivos, mas não para todos".

Em suas lembranças, as tentativas de aplicação da técnica teriam se expandido a conteúdos e disciplinas para as quais a IP não seria aplicável. Como técnica isolada, ela não resolveria os problemas educacionais que consistiam no principal interesse daqueles 
personagens. Soares pontua que se iniciou, no período, uma reação a conhecimentos estrangeiros, especialmente dos EUA, por parte de intelectuais e professores, sobretudo os de tendência de esquerda e opositores do regime militar. No que se refere à análise do comportamento, ela percebia que a IP e os objetivos comportamentais passaram a significar "você está programando as pessoas". Em suas palavras: "Eu acho que prejudicou muito. A história com os ratos e com os pombos. A pessoa falava: isso é pra bicho, isso não é pra gente" (Soares, 23 jan. 2014). Helvécio Pereira (13 jan. 2014) forneceu relato similar: "Houve outras áreas que diziam: 'isso é como ensinar ratos. Vocês não podem ensinar pessoas como ratos'. Sempre teve 'animal é animal, rato é rato, homem é outra coisa'”. Assim, a análise do comportamento, que fora elogiada por contribuir para a construção de objetivos comportamentais, era criticada pelo trabalho experimental com não humanos e pelo foco na manipulação do comportamento.

Além das dificuldades relativas à afiliação teórica à análise do comportamento, houve dificuldades no desenvolvimento de textos programados. Nessa direção, Ione Pereira (21 jan. 2014) afirmou:

A utilização dessa técnica é bem fácil depois que você fez um trabalho todo de análise da disciplina, da matéria, organizou, aplicou, testou etc., não é? Então viu se é boa ou não, se estava caminhando de uma maneira mais ordenada e sistemática para aquele objetivo que você colocou. Mas tudo isso exige um trabalho muito grande, um trabalho de análise, não é?

Ione Pereira nos indica que havia um trabalho árduo na preparação e teste do material programado. Em sua análise, isso era "bastante difícil e complicado", pois exigia que o material produzido fosse interessante para o estudante. Isso seria essencial para que houvesse disposição e "paciência" para participar da atividade. Em suas palavras: "Ele [estudante] ir fazendo a parte dele de respostas e encontrando o conteúdo e reforços que forem necessários" (Pereira, 21 jan.).

Dessa forma, associando as críticas à análise do comportamento, na UFMG, com as dificuldades de preparação do material e a tradução "oficial" do grupo paulista, podemos compreender o fato de o livro de Pereira e Pereira (1969) não ter sido publicado. O texto era utilizado desde 1965 e só foi compilado em 1969. Alguns anos de experiência no uso do material e sua adaptação ao contexto nacional fizeram com que, após a publicação do livro pelos membros de São Paulo, o grupo da UFMG começasse a utilizá-lo como referência.

\section{Considerações finais}

Nosso estudo mostrou que a IP circulou, no Brasil, nas décadas de 1960 e 1970, entre pessoas interessadas em educação, em um contexto marcado (1) pela discussão sobre problemas educacionais e reforma do ensino superior, (2) pela influência estadunidense no campo educacional e (3) pelo fomento ao desenvolvimento científico nacional. A IP foi apropriada como recurso didático a ser utilizado em diferentes níveis de ensino. Houve destaque acentuado da IP como recurso, não como um método de ensino. Isso esteve aliado ao interesse dos brasileiros no planejamento de objetivos comportamentais e ao 
sentimento de segurança que tal abordagem permitia, num contexto cultural no qual se clamava pelo aumento da efetividade do ensino para um contingente populacional em contínuo crescimento.

A apropriação local, na UFMG, ajudou-nos a observar mais claramente que o processo de "indigenização" da análise do comportamento, no Brasil, contou com a circulação de um modelo específico de IP. Isso ocorreu pela filiação teórica ou pelo interesse dos atores que produziram instrumentos de IP no país, por exemplo, Ione Pereira. Ocorreu, também, pela vinculação direta do modelo às propostas skinnerianas, conforme lembranças de Soares. A análise do comportamento e, também, a IP, eram avaliadas criticamente. Houve avaliações positivas, como no caso da criação de objetivos comportamentais, que fomentaram o interesse na utilização desse recurso didático. Ao mesmo tempo, a teoria skinneriana e as dificuldades em programar o ensino, conforme preconizado na IP, foram alvos de críticas que nos ajudam a entender o processo de apropriação ativa, pelos brasileiros, do recurso estadunidense.

É preciso reconhecer, por fim, as limitações metodológicas deste estudo. O que pretendemos foi apresentar uma aproximação ao problema da "indigenização" da tecnologia da IP e, por conseguinte, da própria análise do comportamento, por meio de um estudo de caso. Dessa forma, não podemos extrapolar nossa análise para períodos não estudados ou, então, para outros contextos brasileiros do mesmo período, envolvendo outros autores. Novos estudos precisam ser realizados para compreendermos melhor o processo de apropriação da IP no Brasil, de forma a delinear a participação de outros agentes e investigar as eventuais influências de outras matrizes teóricas sobre a IP. No entanto, esperamos ter identificado um padrão significativo da "indigenização" da análise do comportamento, indo ao encontro das novas formas de historiografia da psicologia surgidas nas últimas décadas.

\section{NOTAS}

${ }^{1}$ Nessa e nas demais citações de textos publicados em outros idiomas, a tradução é livre.

${ }^{2}$ Sugerimos, como exemplos internacionais em IP, Holland, Skinner (1961) e Crowder, Martin (1967). Das produções nacionais, indicamos Muraro (1973) e Witter (1971).

${ }^{3}$ Sobre o comprometimento científico, recomendamos a leitura de Cândido (2014) e a respeito dos embates contra a censura e controle da universidade, sugerimos a leitura de Todorov e Hanna (2010).

${ }^{4}$ Ressalta-se que a instrução personalizada não se confunde com a IP, entretanto, conforme menciona Keller, seria óbvio o paralelo entre a instrução personalizada e a IP. Elas comungavam da perspectiva da progressão individualizada, da preocupação com a delimitação de objetivos comportamentais decorrentes da exposição ao processo de ensino/aprendizagem e da organização sequencial das tarefas. A diferença essencial entre o campo da IP e a instrução personalizada residiria no fato de a última basear-se em atividades similares a trabalhos de casa ou de laboratório convencionais dentro da programação, bem como a exigência de performances variadas, passando por interações sociais com outros estudantes e o professor (Keller, 1968).

${ }^{5}$ O Coluni foi um colégio de nível médio, fundado na UFMG, em 1965. Seu objetivo era fornecer educação considerada de qualidade, pelo corpo de professores da universidade, em nível médio, para que os estudantes se tornassem mais capacitados para o ingresso no ensino superior. 


\section{REFERÊNCIAS}

ARDIGÓ, Fabiano.

Histórias de uma ciência regional. São Paulo: Contexto. 2011.

AZZI, Rodolpho.

Máquinas de aprender: a moda e o medo.

Pesquisa e Planejamento, v.5, p.126-136. 1962.

BENJAMIN, Ludy T. Jr.

A history of teaching machines. American

Psychologist, v.43, n.9, p.703-712. 1988.

BERGVAIL, Pär; JOEL, Nahum.

Informe sobre el Proyecto Piloto de la Unesco. Paris: Unesco. 1967.

BRASIL.

Casa Civil. Lei n.5.540, de 28 de novembro de 1968. Fixa as normas de organização e funcionamento do ensino superior e sua articulação com a escola média, e dá outras providências. Disponível em: http://www. planalto.gov.br/ccivil_03/leis/L5540.htm. Acesso em: 4 maio 2016. 28 nov. 1968.

BRASIL.

Congresso Nacional. Lei n.4.119, de 27 de agosto de 1962. Dispõe sobre os cursos de formação em psicologia e regulamenta a profissão de psicólogo. Disponível em: http:// site.cfp.org.br/wp-content/uploads/2008/08/ lei_1962_4119.pdf. Acesso em: 4 maio 2016. 27 ago. 1962.

BROCK, Adrian.

What is polycentric history of psychology? Estudos e Pesquisas em Psicologia, v.14, n.2, p.646659. 2014.

BROCK, Adrian.

Introduction. In: Brock, Adrian (Org.). Internationalizing the history of psychology. New York: New York University Press. p.1-15. 2006.

CALLENDER, Patricia.

Como preparar e utilizar a instrução programada. Rio de Janeiro: Fórum Editora. 1973.

CAMPOS, Regina Helena; JACÓ-VILELA, Ana Maria; MASSIMI, Marina.

Historiography of psychology in Brazil: pioneer works, recent developments. History of Psychology, v.13, n.3, p.250-276. 2010.

CÂNDIDO, Gabriel Vieira.

O desenvolvimento de uma cultura científica no Brasil: contribuições de Carolina Martuscelli Bori. Tese (Doutorado em Psicologia) Universidade de São Paulo, Ribeirão Preto. 2014.

CARVALHO, Humberto Coelho de.

[Depoimento]. Entrevistador: Eustáquio José de Souza Júnior. Belo Horizonte: Universidade
Federal de Minas Gerais. 1 arquivo mp3 (55 min.). Depoimento concedido ao projeto Circulação da Instrução Programada no Brasil (1960-1980). 11 mar. 2014.

CARVALHO, Humberto Coelho.

Elaboração e avaliação de um texto programado: estudo comparativo da aprendizagem genética de populações através do método de instrução programada aplicado a estudante de nível médio e universitário. Tese (Doutorado em Educação) - Universidade Federal de Minas Gerais, Belo Horizonte, 1973.

CARVALHO, Humberto Coelho. Genética programada. Belo Horizonte: Vega. 1970.

CASTANHEIRA, Sônia dos Santos.

[Depoimento]. Entrevistador: Rodrigo Lopes Miranda. Belo Horizonte: Universidade Federal de Minas Gerais. 1 arquivo mp3 (50 min.). Depoimento concedido ao projeto Laboratórios de Análise do Comportamento no Brasil: Percursos na UFMG na década de 1970. 5 fev. 2009.

CASTELO BRANCO, Paulo Coelho et al. Recepção e circulação: implicações para a pesquisa em história da psicologia. In: Assis, Raquel Martins; Peres, Sávio Passafero. História da psicologia: tendências contemporâneas. Belo Horizonte: Artesã. p.31-49. 2016.

CIRINO, Sérgio Dias; MIRANDA, Rodrigo Lopes; CRUZ, Robson Nascimento.

The beginnings of behavior analysis laboratories in Brazil: a pedagogical view. History of Psychology, v.15, n.3, p.263-272. 2012.

CIRINO, Sérgio Dias; MIRANDA, Rodrigo Lopes; SOUZA JR., Eustáquio José.

The laboratory of experimental psychology: establishing a psychological community at a Brazilian university. Revista Interamericana de Psicología, v.12, n.1, p.135-142. 2012.

CROWDER, Norman Alyson; MARTIN, Grace C. Aventuras en álgebra. Barcelona: Montaner y Simón. 1967.

CUNHA, Luiz Antônio.

Ensino superior e universidade no Brasil. In: Lopes, Eliana Marta Teixeira; Faria Filho, Luciano Mendes; Veiga, Cynthia Greive (Org.). 500 anos de educação no Brasil. Belo Horizonte: Autêntica. p.151-204. 2007.

CUNHA, Luiz Antônio.

A universidade reformada: o golpe de 1964 e a modernização do ensino superior. Rio de Janeiro: Francisco Alves. 1988. 
DAGFAL, Alejandro.

Para una "estética de la recepción" de las ideas psicológicas. Frenia, v.4, n.2, p.7-16. 2004.

DANZIGER, Kurt.

Universalism and indigenization in the history of modern psychology. In: Brock, Adrian (Org.). Internationalizing the history of psychology. New York: New York University Press. p.208-225. 2006.

GAVROGLU, Kostas et al.

Science and technology in the European periphery: some historiographical reflections. History of Science, v.46, n.2, p.153-175. 2008.

GUEDES, Maria do Carmo et al. A introdução da análise do comportamento no Brasil: vicissitudes. Behaviors, v.12, p.41-57. 2008.

GUEDES, Maria do Carmo et al. Institucionalização da análise do comportamento no Brasil: uma perspectiva histórica. Behaviors, v.10, p.17-29. 2006.

HOLLAND, James Gordon; SKINNER, Burrhus Frederic.

The analysis of behavior. New York: McGraw-Hill. 1961.

KELLER, Fred Simmons.

Aprendendo a ensinar: memórias de um professor universitário. São Paulo: Edicon. 1983.

KELLER, Fred Simmons.

Summers and sabbaticals: selected papers on psychology and education. Champaign: Research Press. 1977.

KELLER, Fred Simmons. Good-bye teacher. Journal of Applied Behavior Analysis, v.1, n.1, p.79-89. 1968.

KELLER, Fred Simmons; BORI, Carolina Martuscelli; AZZI, Rodolpho.

Um curso moderno de psicologia. Ciência e Cultura, v.16, n.4, p.397-399. 1964.

KELLER, Fred Simmons; SHERMAN, J. Gilmour. The Keller Plan handbook: essays on personalized system of instruction. Menlo Park: W.A. Benjamin. 1974.

KERBAUY, Rachel Rodrigues.

O cientista que ensinava. Psicologia USP, v.7, n.12, p.225-245. 1996.

KERBAUY, Rachel Rodrigues. Análise experimental do comportamento: exercícios de laboratório com pombos. São Paulo: [s.n.] 1970.

KRAFTZIK, Maria Luiza Alcântara. Acordo MEC/Usaid: a Comissão do Livro Técnico e do Livro Didático (Colted). Rio de
Janeiro: Dissertação (Mestrado em Educação) Universidade do Estado do Rio de Janeiro, Rio de Janeiro. 2006.

MATOS, Maria Amélia.

Behaviorismo metodológico e behaviorismo radical. In: Rangé, Bernard (Org.). Psicoterapia comportamental e cognitiva: pesquisa, prática, aplicações e problemas. Campinas: Editorial Psy. p.27-34. 1998.

MENDONÇA, Ana Waleska P.C.

A universidade no Brasil. Revista Brasileira de Educação, v.14, n.2, p.131-150. 2000.

MENDONÇA, Ana Waleska P.C. et al.

Pragmatismo e desenvolvimentismo no pensamento educacional brasileiro dos anos de 1950/1960. Revista Brasileira de Educação, v.11, n.31, p.96-113. 2006.

MIRANDA, Rodrigo Lopes.

Laboratórios de Análise do Comportamento no Brasil: percursos na UFMG na década de 1970. Dissertação (Mestrado em Educação) Universidade Federal de Minas Gerais, Belo Horizonte. 2010.

MOTTA, Rodrigo Sá Patto.

As universidades e o regime militar. Rio de Janeiro: Zahar. 2014.

MURARO, Luis Inácio Tadeu.

Formação técnica em instrução programada. Rio de Janeiro: Vozes. 1973.

PAIVA, Edil Vasconcelos; PAIXÃO, Lea Pinheiro. Pabaee (1956-1964): a americanização do ensino elementar? Niterói: Eduff. 2002.

PEREIRA, Helvécio Botelho.

[Depoimento]. Entrevistador: Eustáquio José de Souza Júnior. Belo Horizonte: Universidade Federal de Minas Gerais. 1 arquivo mp3 (50 min.). Depoimento concedido ao projeto Circulação da Instrução Programada no Brasil (1960-1980). 13 jan. 2014.

PEREIRA, Helvécio Botelho. Instrução programada: teoria e prática. Rio de Janeiro: Forense. 1970.

PEREIRA, Ione Scarpelli.

[Depoimento]. Entrevistador: Eustáquio José de Souza Júnior. Belo Horizonte: Universidade Federal de Minas Gerais. 1 arquivo mp3 (50 min.). Depoimento concedido ao projeto Circulação da Instrução Programada no Brasil (1960-1980). 21 jan. 2014.

PEREIRA, Ione Scarpelli; PEREIRA, Helvécio Botelho.

Psicologia da aprendizagem: condicionamentos clássico e operante. Belo Horizonte:

Departamento de Ciências Aplicadas à 
Educação, Faculdade de Educação, Universidade Federal de Minas Gerais. 1969.

PICKREN, Wade.

Indigenization and the history of psychology. Psychological Studies, v.54, n.2, p.87-95. 2009.

PICKREN, Wade; RUTHERFORD, Alexandra. Rumo a uma história global da psicologia. In: Araujo, Saulo. História e filosofia da psicologia: perspectivas contemporâneas. Juiz de Fora: Editora UFJF. p.57-66. 2012.

PRATT, Mary Louise.

Olhos do império: relatos de viagem e transculturação. Bauru: Edusc. 1999.

PRESSEY, Sidney Leavitt.

A simple apparatus which gives tests and scores - and teaches [1926]. In: Lumsdaine, Arthur A.; Glaser, Robert (Ed.). Teaching machines and programmed learning: a source book. Washington: National Education Association. p.37-41. 1960a.

PRESSEY, Sidney Leavitt.

A machine for automatic teaching of drill material [1927]. In: Lumsdaine, Arthur A.; Glaser, Robert (Ed.). Teaching machines and programmed learning: a source book. Washington: National Education Association. p.42-46. 1960 b.

PRESSEY, Sidney Leavitt.

A third and fourth contribution toward the coming "industrial revolution" in education [1932]. In: Lumsdaine, Arthur A.; Glaser, Robert (Ed.). Teaching machines and programmed learning: a source book. Washington: National Education Association. p.47-51. 1960c.

RAJ, Kapil.

Beyond postcolonialism... and postpositivism: circulation and the global history of science. Isis, v.104, n.2, p.337-347. 2013.

RAJ, Kapil.

Relocating modern science: circulation and the construction of knowledge in South Asia and Europe, 1650-1900. New York: Palgrave Macmillan. 2007.

REESE, Ellen P.

Experiments in operant behavior. New York: Appleton-Century-Crofts. 1964.

ROTA JR., César.

Recepção e circulação dos testes de inteligência na Escola de Aperfeiçoamento de Professores de Belo Horizonte (1929-1946). Tese (Doutorado em Educação) - Universidade Federal de Minas Gerais, Belo Horizonte. 2016.
SALMERON, Roberto Aureliano.

A universidade interrompida: Brasília 1964-1965.

Brasília: Editora Universidade de Brasília. 2007.

SKINNER, Burrhus Frederic.

A matter of consequences. New York: Alfred A. Knopf. 1983.

SKINNER, Burrhus Frederic.

The science of learning and the art of teaching. Harvard Educational Review, v.24, p.86-97. 1954.

SOARES, Magda Becker.

[Depoimento]. Entrevistador: Eustáquio José de Souza Júnior. Belo Horizonte: Universidade Federal de Minas Gerais. 1 arquivo mp3 (50 min.). Depoimento concedido ao projeto Circulação da Instrução Programada no Brasil (1960-1980). 23 jan. 2014.

SOUZA, Roger Marchesini de Quadros.

Fracasso escolar, a construção de um tema. Revista Múltiplas Leituras, v.4, n.1, p.53-69. 2011.

SOUZA JR., Eustáquio José.

Circulação da instrução programada no Brasil (1960-1980). Tese (Doutorado em Educação)

- Universidade Federal de Minas Gerais, Belo Horizonte. 2015.

TODOROV, João Cláudio.

Behaviour analysis in Brazil. Avances en

Psicología Latinoamericana, v.24, p.29-36. 2006.

TODOROV, João Cláudio; HANNA, Elenice Seixas.

Análise do comportamento no Brasil. Psicologia: Teoria e Pesquisa, v.26, n.esp., p.143-153. 2010.

VASCONCELLOS, Maria José Esteves de. [Depoimento]. Entrevistador: Rodrigo Lopes Miranda. Belo Horizonte: Universidade Federal de Minas Gerais. 1 arquivo mp3 (50 min.). Depoimento concedido ao projeto Laboratórios de Análise do Comportamento no Brasil: Percursos na UFMG na década de 1970. 5 mar. 2009.

WITTER, Geraldina Porto.

Privação cultural: instrução programada. São Paulo: Vetor. 1971.

WITTER, Geraldina Porto; KERR, Warwick Estevam; FONSECA, Ozório José Menezes. Cartilha da Amazônia: livro do professor. Manaus: Secretaria de Educação e Cultura do Estado do Amazonas, Instituto Nacional de Pesquisas da Amazônia. 1977. 